\title{
Impact of local conditions and machine management on grape harvest quality
}

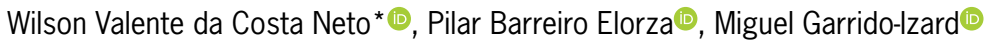

Universidad Politecnica de Madrid/ETSIAAB - Depto. Ingeniería Agroforestal, Avda. Complutense, 3 - 28040 Madrid - España.

*Corresponding author<wilsonneto@unipampa.edu.br>

Edited by: Thiago Libório Romanelli

Received December 20, 2017

Accepted May 10, 2018

\begin{abstract}
Since its inception approximately 50 years ago, the grape harvester has been one of the machines responsible for the expansion of viticulture in the world. In Spain, harvesters were introduced in the 1990s (there are now approximately 3,000 machines there as of 2017), while they were introduced in Brazil in 2010. Harvest mechanization requires specific crop adaption and new work features that deserve to be analysed from their very beginnings. The aim of this study was to evaluate the management of four commercial grape harvest machines under actual field conditions on an intercontinental basis in two locations in Brazil and Spain. Machine performance measured by work (ha $\mathrm{h}^{-1}$ ) and processing capacity $\left(\mathrm{kg} \mathrm{h}^{-1}\right)$, together with field efficiency (\%) and task quality, as measured by grape losses (\%), in soil and plant, as well as must release (\%), were considered in relation to plot geometry, adaption of plots to mechanical harvesting, and machine type, in order to assess whether the initial steps towards harvest mechanization in Brazil have led to similar performance and quality levels compared to Spain, which represents an example of well-established mechanization. The theoretical work capacities were similar for towed equipment in both countries $\left(0.81 \mathrm{ha} \mathrm{h}^{-1}\right.$ in Brazil and $0.87 \mathrm{ha} \mathrm{h}^{-1}$ in Spain) and lower compared to self-propelled capacity $\left(1.34 \mathrm{ha} \mathrm{h}^{-1}\right)$. Significant differences were observed in terms of losses of grapes and must, with the highest values prevailing in Brazil (2 \% grape losses in the ground; up to $23 \%$ of the plant undetached grapes and must losses of 2-4\% (per kg vine productivity).
\end{abstract}

Keywords: grape wine, mechanization, performance, trellising system, transcontinental approach

\section{Introduction}

Commercial grape harvest mechanization started in Spain in the 1990s (Figure 1). The present stage of grape harvest mechanization has witnessed its highest-growth rate (152 self-propelled machines per year) (MAGRAMA, 2016). Conversely, grape harvest mechanization begun in Brazil in 2010, had only 4 units active in 2016 at the national level (3 towed and 1 self-propelled) all owned by 2 wineries (Costa Neto et al., 2017).

The theoretical work capacity of grape harvesters has been bounded in several countries in a range of 0.34 to $0.9 \mathrm{ha} \mathrm{h}^{-1}$, Trocoso et al. (2002); Pezzi and Martelli (2015), while field efficiency ranks between 40 and 80 $\%$ according to plot configuration, with typical working ground speeds between 3 and $4 \mathrm{~km} \mathrm{~h}^{-1}$. A precise assessment of work capacity and field efficiency has demonstrated itself to be a relevant issue, as the differences between declared and measured data can be above $40 \%$ as identified by Vollmer and Schwarz (2013) in a study conducted in Germany.

According to Clary et al. (1990) mechanical harvesting yields quantities of fruit harvested similar to those obtained by manual harvesting, with lower percentages of stems. Trocoso et al. (2002), in Chile reports that mechanical harvesters account for approximately $5 \%$ of soil grape losses, values far above those identified by Pezzi and Caprara, 2009; and Pezzi and Martelli, 2015 where ground losses were found to be slightly higher in towed rather than self-propelled machines (2\% and $1 \%$, respectively) with similar quantities of grape remaining on the vines.

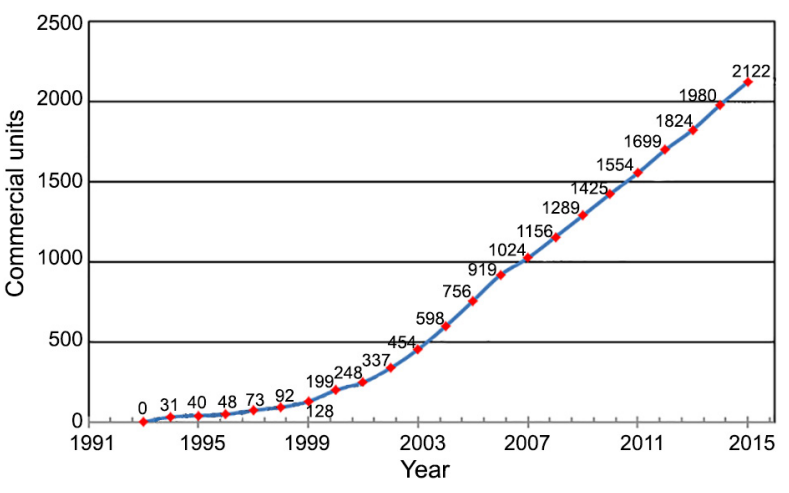

Figure 1 - Evolution of the number of self-propelled grape harvesters in Spain.

Trocoso et al. (2002); and Hendrickson and Oberholster (2017) corroborated that the harvesting method has little influence on differentiating between wines for the same varieties of grapes. Similar results were found by Arfelli et al. (2010), emphasizing that the differences found between the wines are due to grape characteristics, inadequate grape harvester settings and post-harvest handling.

The aim of this study was to evaluate the management of four commercial grape harvest machines under actual field conditions on an intercontinental basis (Brazil and Spain), and assess whether the initial steps towards harvest mechanization in Brazil lead to similar performance compared to advanced mechanization stages elsewhere the task is carried out by service providers. 


\section{Materials and Methods}

\section{Adaptation of plots to mechanized harvest}

The 13 plots in Brazil were situated in two locations: Fortaleza do Seival $30^{\circ} 47^{\prime} 00^{\prime \prime} \mathrm{S}$ and $55^{\circ} 22^{\prime} 09^{\prime \prime} \mathrm{W}$ (8 plots), altitude $278 \mathrm{~m}$ and Almaden $31^{\circ} 23^{\prime} 43^{\prime \prime} \mathrm{S}$ and $53^{\circ} 46^{\prime} 03^{\prime \prime} \mathrm{W}$ (6 plots), altitude $186 \mathrm{~m}$. They were planted for mechanized purposes in 2008 and 2006, respectively, (Figure 2A and B), while in Spain the 14 plots were at two other locations: Albacete $38^{\circ} 58^{\prime} 42^{\prime \prime} \mathrm{N}$ and $1^{\circ} 52^{\prime} 32^{\prime \prime} \mathrm{W}$ (6 plots), altitude $685 \mathrm{~m}$ and Cabezamesada 39 47'10" $\mathrm{N}$ and $3^{\circ} 05^{\prime} 10^{\prime \prime} \mathrm{W}$ (9 plots), altitude $725 \mathrm{~m}$. Ten plots had been planted in 2008 directly for mechanical harvesting, and 5 plots (planted in 1987, Figure 2C) had been reconfigured (by the owner) in 2014 from manual to mechanical harvesting by incorporating trellises (Figure 2D).

Both sites in Spain belong to the Castilla-La Mancha region, which represents the widest production area (445142 ha) and largest production (2.9 Mt) in Spain, (MAGRAMA, 2016).

\section{Characterization of plots}

A total of 13 plots were assessed in Brazil (18.4 ha) in Feb 2016, while 15 were analysed in Spain (20.4 ha) in Sept 2016 (Table 1). In both cases, the most frequent geometry of the plots corresponded to rectangular shapes: 11 of 13 and 12 of 15 in Brazil and Spain, respectively. Rectangular plots were classified as $2: 1$ or $4: 1$, considering their length to width ratio.
The management of vineyards is country dependent; in Spain it is typical to do some soil preparation and maintain the soil surface without vegetation cover (Figure 2C) to eliminate invasive plants, reducing the competition for nutrients and water and incorporating the organic matter into the soil (grader grids, scarifiers and cultivators are usually employed). In contrast, vineyard management in Brazil makes use of vegetal cover (Figure 2A), and even incorporates additional grass species which contribute to nitrogen fixing in the soil. This is due to the rainy environment, which records show is approximately 1,400 $\mathrm{mm}$ per year in Brazil. The average annual rainfall for the Spanish plots is approximately $400 \mathrm{~mm}$ per year in the area of study, though support irrigation is allowed to a limited extent.

Vine frames were measured individually for each plot and were found to be higher on average in Spain compared to Brazil, with measurements of 3.98 and $5.89 \mathrm{~m}^{2}$ for red and white grapes in Spain, respectively, versus 2.69 and $3.03 \mathrm{~m}^{2}$ in Brazil, respectively, which is

Table 1 - Characterization of plot geometry (Witney, 1995).

\begin{tabular}{lcccc}
\hline & Brazil & Field & Spain & Field \\
\hline Square 1:1 & \multicolumn{3}{c}{ ha } & ha \\
Rectangle 2:1 (R21) & 6 & 2.8 & 1 & 0.7 \\
Rectangle 4:1 (R41) & 5 & 4.1 & 5 & 8.2 \\
Standard & 1 & 1.8 & 7 & 8.5 \\
\hline
\end{tabular}

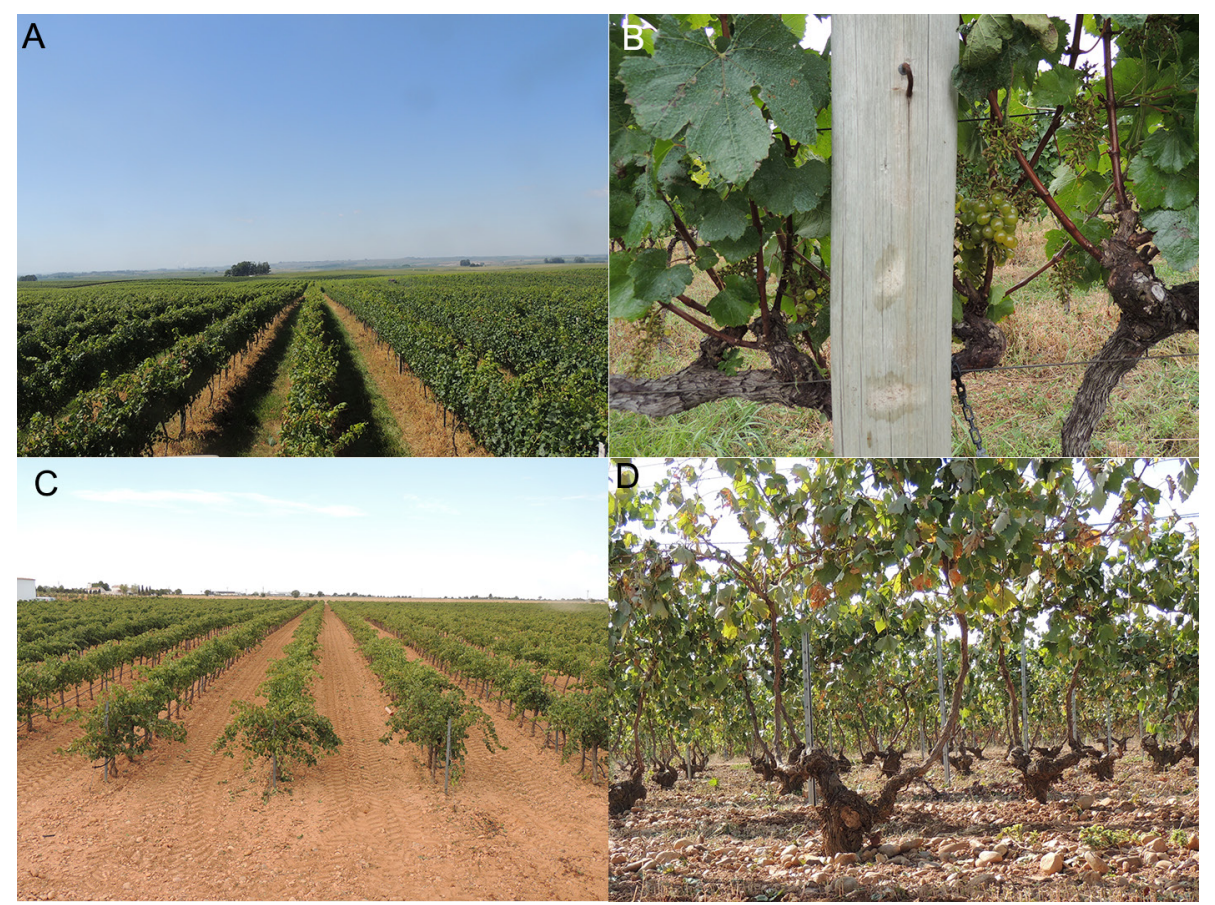

Figure 2 - Characterization of plots with special reference to differences between countries. For Brazil: (A) refers to the use of green cover and (B) provides a detail on the wood sticks (10 or $20 \mathrm{~cm}$ diameter), in this case $20 \mathrm{~cm}$. For Spain: (C) refers to no green cover, and (D) to an example of reconfigured vines. 
as expected given the lower water availability in Spain. However, vine productivity $(\mathrm{kg})$, assessed at random places for each plot, was found to be higher in Spanish fields compared to those in Brazil: 4.66 and $9.42 \mathrm{~kg}$ for red and white grapes, respectively, versus 2.47 and $2.96 \mathrm{~kg}$ in Brazil (Table 2). The number of dead or unproductive vines per plot was found to be higher in Spanish fields compared to those in Brazil: approximately $8 \%$ and $2 \%$, respectively. The relevance of differences in vine productivity and vine frames between countries $(F=80.53)$ and grape types $(\mathrm{F}=23.89)$ affects machine performance and is considered accordingly later in this paper.

Grape varieties grown in Brazil included Tempranillo for red grapes, and Riesling Italico and Chardonnay for white grapes. In the case of Spain, the varieties included Tempranillo, Syrah and Merlot for red grapes, and Airen and Macabeo for white grapes.

\section{Machines assessed}

Two towed Pellenc grape harvesters, both owned by wineries, were used in Brazil. One of them corresponded to Model 8050, with 280 h of previously accumulated work (eight plots, among which six were rectangular plots $3(2: 1)+3(4: 1))$, and the others corresponded to Model 3052, with 1,200 h of previously accumulated work (five plots, all rectangular, 3(2:1) + 2(4:1). Two grape harvesters were also used in Spain, corresponding to $\mathrm{CNH} 9090 \mathrm{X}$ with $320 \mathrm{~h}$ of previously accumulated work (12 plots, 11 rectangular, 5(2:1) and $6(4: 1)$, and Pellenc 8015, with 640 h of previously accumulated work (2 plots, squares); the former was selfpropelled, while the latter corresponded to a towed configuration (both corresponding to external services enterprises). Pellenc machines allowed for the regulation of vibration frequency and amplitude, as well as head opening, while the $\mathrm{CNH}$ machine was adjustable only in terms of vibration frequency. All machines used during actual harvesting followed local practices. Table 3 shows the majority of the relevant technical details of the grape harvester design and settings.

\section{Machine performance analysis}

Machine performance (work capacity - ha $\mathrm{h}^{-1}-$ and field efficiency - \% -) was computed based on DGPS data (position and speed). The antennas were configured to record several NMEA messages (\$ GPGGA, \$ GPVTG, \$ PGRMM) with frequencies $0.5 \mathrm{~Hz}$ (Garmin model 18X in the evaluations in Brazil) and $1 \mathrm{~Hz}$ (Garmin 17X in the evaluations in Spain). The antennas were installed in the center of the grape harvesters (the cultivation line) so as to evaluate quality field performance; ED50 geoid was used for the northern hemisphere, while WGS84 was considered for the southern hemisphere. The Universal Transverse Mercator Coordinates (UTM) were computed accordingly.

Following the procedure described by Costa Neto et al. (2017), dedicated Matlab routines allowed for automated identification of crop rows, headlines, and stops; in other words, these routines made possible the deter-
Table 2 - Statistical characterization of vineyards between countries. F values refer to Fisher under ANOVA.

\begin{tabular}{lccccc}
\hline Country & Type & $\begin{array}{c}\text { Vine } \\
\text { yield }\end{array}$ & $\begin{array}{c}\text { Vine } \\
\text { frame }\end{array}$ & $\begin{array}{c}\text { Dead } \\
\text { vines }\end{array}$ & $\begin{array}{c}\text { Average } \\
\text { productivity }\end{array}$ \\
\hline Spain & Red & kg & $\mathrm{m}^{2}$ & $\%$ & $\mathrm{~kg} \mathrm{ha}^{-1}$ \\
Spain & White & 9.66 & 3.98 & 8.8 & 10601 \\
Brazil & Red & 2.47 & 2.69 & 1.5 & 8866 \\
Brazil & White & 2.96 & 3.03 & 2.8 & 9606 \\
& F country & $21.24^{* *}$ & $80.53^{* *}$ & $8.15^{* *}$ & $\mathrm{~ns}$ \\
${ }^{* *} \mathrm{p}<0.01 ;$ ns $=$ not significant. & & $\mathrm{ns}$ & $\mathrm{ns}$ \\
\hline
\end{tabular}

Table 3 - Technical details of grape harvesters. Recommended and actual settings.

\begin{tabular}{lcccc}
\hline Model & 3052 & 8050 & 8015 & $9090 \mathrm{X}$ \\
\hline $\begin{array}{l}\text { Theoretical work capacity } \\
\text { WCt (manufacturer) }\end{array}$ & $\begin{array}{l}\text { 10-15 t h-1 } \\
\text { Power (kW) }\end{array}$ & $10-15 \mathrm{t} \mathrm{h}^{-1}$ & $10-15 \mathrm{t} \mathrm{h}^{-1}$ & $20 \mathrm{t} \mathrm{h}^{-1 *}$ \\
Tractor & 55 & 55 & 55 & 175 \\
Max. speed $\left(\mathrm{km} \mathrm{h}^{-1}\right)$ & 4.7 & 7 & 7 & 7 \\
$\mathrm{~N}^{\circ}$ of shakers & 16 & 10 & 10 & 24 \\
Sealing & $32 \mathrm{scales}$ & $38 \mathrm{scales}$ & $32 \mathrm{scales}$ & 136 baskets \\
Grape tank & $3000 \mathrm{l}$ & $3000 \mathrm{l}$ & $3000 \mathrm{l}$ & $3200 \mathrm{l}$ \\
Turnover $\left(90^{\circ}\right)$ & $40 \%$ & $40 \%$ & $45 \%$ & $100 \%$ \\
High fans: & Yes & No & No & Yes \\
\hline
\end{tabular}

${ }^{*}$ Value informed by the user.

mination of total working and effective time according to the following definitions from Hunt and Wilson (2015): in-row time (In row, s), defined as the duration the machine remains inside the row; avoidable dead time (TME, s), defined as the period the machine stops inside a row; accessory time (TA, s) defined as the sum of all unavoidable periods such as manoeuvring on the headland and unloading; and effective time (TE, s), defined as the operating time (i.e, In_row minus TME). As a result, field efficiency $(\mathrm{FE}, \%)$ is computed according to equation 1as follows:

$F E(\%)=100 * T E *(T E+T A)^{-1}$

where $T E=$ effective time $(\mathrm{s})$ and $T A=$ accessory time $(\mathrm{s})$, while theoretical work capacity $\left(W C t\right.$, ha $\left.h^{-1}\right)$ is calculated as:

$W C t=b * v * 10^{-1}$

where: $b=$ is row width $(\mathrm{m}) ; v=$ ground speed $(\mathrm{km}$ $\left.\mathrm{h}^{-1}\right)$; and $v$ the average non-zero In_row ground speed $\left(\mathrm{km} \mathrm{h}^{-1}\right)$.

Actual work capacity $\left(W C a\right.$, ha $\left.^{-1}\right)$ is then derived from previous values, such as:

Act_FE $=\left(\frac{\Sigma T E}{\Sigma T M E+\Sigma T A+\Sigma T E}\right) * 100$ 
where: $A c t \_F E=$ actual efficiency $(\%)$ and $T M E=$ avoidable dead time (s). WCa is calculated by:

$W C a=\frac{W C t * A c t \_F E}{100}$

and machine processing capacity $\left(\mathrm{MPCa}, \mathrm{kg} \mathrm{h}^{-1}\right)$ by:

$$
M P C a=\left(\frac{\text { Prod } .}{W C a}\right)
$$

where: Prod. $=$ production of grapes $\left(\mathrm{kg} \mathrm{ha}^{-1}\right)$

Figure 3 presents an example of machine trajectories according to DGPS data with machine stop events indicated as circles; the color refers to stop duration (s). Circles inside the rows correspond to TME values, and it can be seen that in this plot 5 stops of less than 200s occurred and the stops at the headers of the lines $(<200$ s) indicate small adjustments, such as starting the harvesting mechanism and alignment to start the operation while those in headlands refer to unloading operations.

\section{Quality of harvesting}

Grape losses were assessed for each plot in an area of $18 \mathrm{~m}^{2}$, centred in a row line once grapes lying on the soil before the harvest had been removed. After harvesting, grapes lying on the soil were counted and

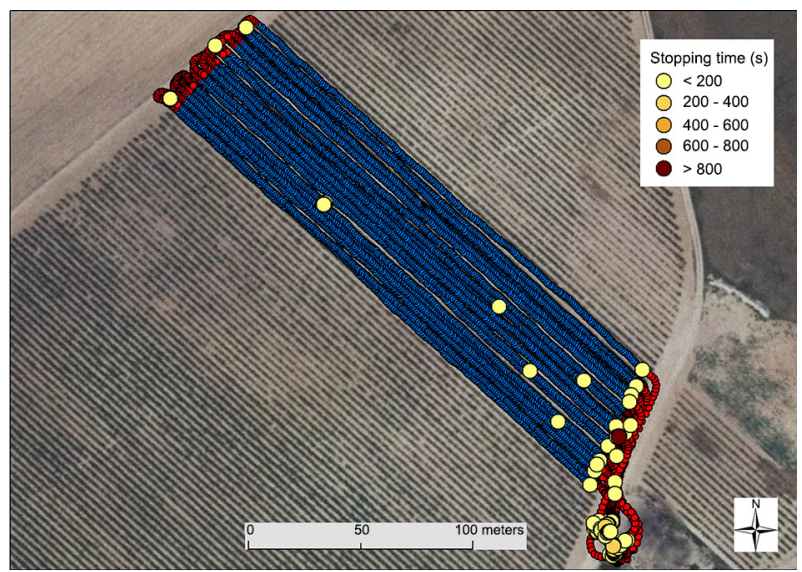

Figure 3 - Example of machine trajectories in plot number 16 (R41). Red lines refer to headland, blue lines to crop rows, and circles to machine stops with color referring to stop duration in seconds. weighed, as well as those remaining on the vines. Grape losses (soil and plant) are expressed as percentages of vine productivity. The former is related to machine harvester head, while the latter is an indicator of insufficient vibration. The plant/soil ratio of grape losses is also computed. Harvest efficiency (\%) is computed as $100 \%$ minus soil and plant losses (\%).

Must release was evaluated by means of water sensitive papers during harvesting in 14 plots 16 in Brazil and 8 in Spain) with varying harvester settings (shaking frequency and amplitude) and grape types (white or red). Water sensitive papers were arranged as shown in Figure 4, two being positioned on the ground $60-80 \mathrm{~cm}$ away from the stem (A-B); one on the stem with a height of $30-40 \mathrm{~cm}(\mathrm{C})$; two in the production string (D-F); and two more in the canopy area, height 1.30-1.50 m (E-E1), as shown in Figure 4. Image analysis was performed according to Costa Neto et al. (2017), providing the percentage surface in blue (reacting to moisture). To assess average must losses per vine in terms of total canopy and soil coverage $(\%)$, a standard surface was considered per vine: $0.96 \mathrm{~m}^{2}$ at soil level (A and B) and 2.88 $\mathrm{m}^{2}$ for the canopy (C to $\mathrm{F}$ ). Must release could then be normalized regarding vine productivity and computed as a percentage of canopy coverage per kg grape production $\left(\% \mathrm{c} \mathrm{kg}^{-1}\right)$ to compensate for grape type and country differences.

\section{Results and Discussion}

\section{Machine performance}

Table 4 presents the following parameters for the characterization of machine performance in Brazil and Spain: average in row ground speed $\left(\mathrm{km} \mathrm{h}^{-1}\right)$ together with corresponding standard deviation $\left(\mathrm{km} \mathrm{h}^{-1}\right)$ and number of data; row width (m), and WCt (ha h $\left.\mathrm{h}^{-1}\right)$, clustered by machine type and model. Generally, theoretical WCt (ha $\mathrm{h}^{-1}$ ) is higher in Spain due to higher in row ground speed (self-propelled models) and distance between lines (m) compared to Brazil. The average WCt (ha $\mathrm{h}^{-1}$ ) was 1.34 ha $\mathrm{h}^{-1}$ in Spain, with self-propelled machines compared to 0.82 and $0.88 \mathrm{ha} \mathrm{h}^{-1}$ for towed harvesters in Spain and Brazil, respectively. In Spain, there is a notable increase in ground speed in model 9090X (self-propelled) for red

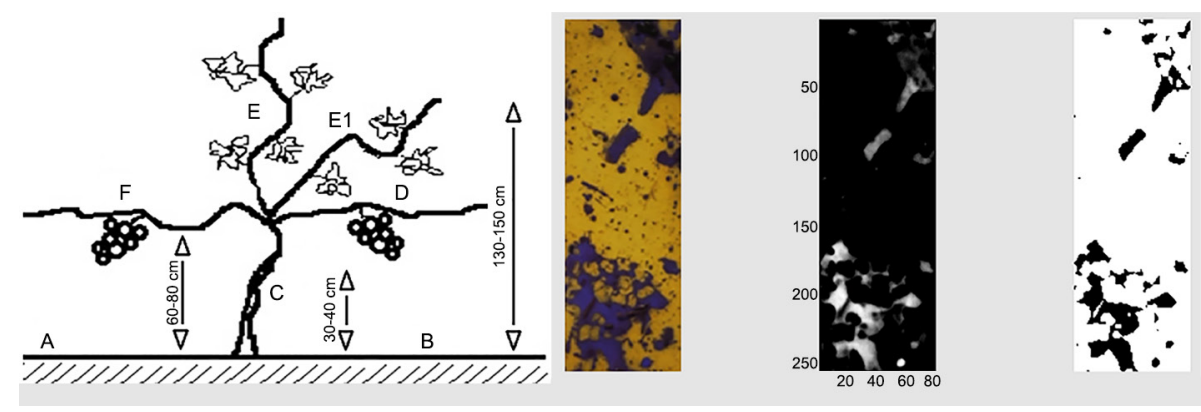

Figure 4 - Positioning the hydrosensitive papers and image treatments. 
Table 4 - Performance of the mechanical harvest in the two countries. Ground speed: average, (standard deviation) and number of data; row width and theoretical work capacity (WCt) and grape type (W for white and R for red).

\begin{tabular}{|c|c|c|c|c|c|c|c|}
\hline \multicolumn{4}{|c|}{ Brazil } & \multicolumn{4}{|c|}{ Spain } \\
\hline & $\begin{array}{c}\text { Ground speed } \\
\left(\mathrm{km} \mathrm{h}^{-1}\right) \text { average and data }\end{array}$ & $\begin{array}{l}\text { Row } \\
\text { width }\end{array}$ & $\begin{array}{l}\text { WCt }\left(\mathrm{ha} \mathrm{h}^{-1}\right) \\
\text { /grape type }\end{array}$ & & $\begin{array}{c}\text { Ground speed } \\
\left(\mathrm{km} \mathrm{h}^{-1}\right) \text { average and data }\end{array}$ & $\begin{array}{l}\text { Row } \\
\text { width }\end{array}$ & $\begin{array}{l}\text { WCt }\left(\mathrm{ha} \mathrm{h}^{-1}\right) \\
\text { /grape type }\end{array}$ \\
\hline \multirow{6}{*}{$\begin{array}{l}3052 \\
\text { Towed }\end{array}$} & & $\mathrm{m}$ & & \multirow{14}{*}{$\begin{array}{l}9090 \mathrm{X} \\
\text { Self-propelled }\end{array}$} & & $\mathrm{m}$ & \\
\hline & $3.4 \pm 0.57901$ & 3.0 & $1.03 \mathrm{~W}$ & & $4.0 \pm 0.544408$ & 3.0 & $1.19 \mathrm{~W}$ \\
\hline & $3.6 \pm 0.36619$ & 3.0 & $1.07 \mathrm{~W}$ & & $3.6 \pm 0.410080$ & 3.0 & $1.08 R$ \\
\hline & $3.6 \pm 0.46670$ & 3.0 & $1.08 \mathrm{~W}$ & & $3.7 \pm 0.517610$ & 3.0 & $1.12 R$ \\
\hline & $3.7 \pm 0.31379$ & 2.8 & $1.05 \mathrm{~W}$ & & $4.3 \pm 0.313864$ & 3.0 & $1.28 R$ \\
\hline & $3.3 \pm 0.51746$ & 2.8 & $0.93 \mathrm{~W}$ & & $4.0 \pm 0.34820$ & 3.0 & $1.21 \mathrm{~W}$ \\
\hline \multirow{10}{*}{$\begin{array}{l}8050 \\
\text { Towed }\end{array}$} & $3.2 \pm 0.12417$ & 3.0 & $0.96 \mathrm{~W}$ & & $4.7 \pm 0.1720$ & 3.0 & $1.41 R$ \\
\hline & $3.3 \pm 0.21539$ & 2.8 & $0.91 W$ & & $4.5 \pm 0.26530$ & 3.0 & $1.35 R$ \\
\hline & $3.3 \pm 0.21270$ & 2.0 & $0.65 W$ & & $4.7 \pm 0.35756$ & 3.0 & $1.40 R$ \\
\hline & $3.2 \pm 0.2976$ & 2.0 & $0.63 W$ & & $4.7 \pm 0.22578$ & 3.0 & $1.46 R$ \\
\hline & $3.3 \pm 0.25340$ & 2.5 & $0.82 W$ & & $4.7 \pm 0.22450$ & 3.0 & $1.50 R$ \\
\hline & $3.3 \pm 0.21862$ & 2.5 & $0.83 W$ & & $4.7 \pm 0.37744$ & 3.0 & $1.42 R$ \\
\hline & $3.2 \pm 0.25925$ & 2.2 & $0.70 R$ & & $5.0 \pm 0.35220$ & 3.0 & $1.50 R$ \\
\hline & $3.2 \pm 0.22290$ & 2.2 & $0.71 R$ & & $4.9 \pm 0.42200$ & 3.0 & $1.47 R$ \\
\hline & & & & \multirow{2}{*}{$\begin{array}{l}8015 \\
\text { Towed }\end{array}$} & $2.7 \pm 0.519420$ & 3.0 & $0.82 W$ \\
\hline & & & & & $2.7 \pm 0.526920$ & 3.0 & $0.81 W$ \\
\hline
\end{tabular}

compared to white grapes, as had been expected due to their lower yield (Table 2): $4 \mathrm{~km} \mathrm{~h}^{-1}$ and $4.5 \mathrm{~km} \mathrm{~h}^{-1}$, with a maximum of 4.0 and $5 \mathrm{~km} \mathrm{~h}^{-1}$, respectively. Ground speed is also shown to be significantly lower for white grapes harvested via towed machines in Spain compared to Brazil ( $\mathrm{F}=18.9, p<0.01$, data not shown), with values of $2.7 \mathrm{~km} \mathrm{~h}^{-1}$ and $3.3 \mathrm{~km} \mathrm{~h}^{-1}$, respectively, which is also consistent with lower yields in Brazil compared to Spain (Table 2). In row ground speed variability remains very homogeneous in all cases, at approximately $10 \%$ $\mathrm{CV}$. The substantial amount of data (Table 4) indicates the features per plot.

The values of ground speed found in this study indicate that the self-propelled machine (9090X) was handled by the service provider at a higher speed (up to $5 \mathrm{~km} \mathrm{~h}^{-1}$ ) compared to previous reports with a speed of $4.2 \mathrm{~km} \mathrm{~h}^{-1}$ (Troncoso et al., 2002); and 3-4 $\mathrm{km} \mathrm{h}^{-1}$ (Catania et al., 2009).

It is relevant to analyse whether the maximum theoretical processing capacity $\left(\mathrm{kg} \mathrm{h}^{-1}\right)$ reached for each machine type is an indicator of optimal ground speed. In this sense, the maximum PCt $\left(\mathrm{kg} \mathrm{h}^{-1}\right)$ in towed machines (Brazil and Spain) was 10,374 and 12,567 $\mathrm{kg} \mathrm{h}^{-1}$ (69\% and $84 \%$ of recommended maximum) compared to $23,272 \mathrm{~kg} \mathrm{~h}^{-1}$ (above $100 \%$ of the recommended maximum) in a self-propelled harvester in Spain (data computed based on Table 3 and Table 4). These values point to an excessive ground speed for the self-propelled harvester in Spain, while it remains sub-optimal in Brazil.

Table 5 shows TME values (s) and \% of TE for each plot, clustered by machine type (model) and adaption of plot to mechanical harvesting (reconfigured and labelled R). Generally, in Spain TME (\%) was higher for reconfigured plots (above $10 \%$, 4 out of 6 plots) than for adapted ones $(0-3 \%, 9$ out of 10 plots). It is important to state that the TME in Brazil for this study in Feb 2016 (less than $16 \%$ ) were much better than those provided in a previous study (Mar 2015, 50-80 \% of TE (Costa Neto et al., 2017), indicating that the performance of grape harvest mechanization is improving. It is readily understood that TME relates to poor vine maintenance, and that excessive ground speed, though having poor tractor trafficability may also occur under wet soil conditions (Figure 5 corresponding to Plot 2 with TME below 16 $\%$ of TE). In previous studies, there was no TME inside vine rows, and ground speed and yields were lower in those studies (3-4 $\mathrm{km} \mathrm{h}^{-1}$ and yield below $8 \mathrm{t} \mathrm{ha}^{-1}$ ). Pezzi and Caprara (2009) and Caprara and Pezzi (2011) did not report the occurrence of such events, even with $21 \mathrm{t}$ $\mathrm{ha}^{-1}$ of yield, since ground speed was set to $2.8 \mathrm{~km} \mathrm{~h}^{-1}$. This fact points to the importance of adequate training for machine operators. It is worth stating that our TME values rely on an analysis of actual harvesting conditions and not on dedicated field experiments (Pezzi and Caprara, 2009; Caprara and Pezzi, 2014).

Actual field efficiency $(\%)$ per plot shows a very wide range of values despite the geometry $(2: 1$; Figure $6 \mathrm{~A}$ and $\mathrm{C}$ or $4: 1$; Figure $6 \mathrm{~B}$ and D / and machine type towed versus self-propelled, (Table 6) where values are ranked in descending order of $\mathrm{FE} \mathrm{( \% ).} \mathrm{The} \mathrm{highest} \mathrm{FE}$ value is always poorer for 2:1 plot geometry than for that of $4: 1$ (79\% and $67 \%$ compared to $85 \%$ and $83 \%$ ), which indicates the potential improvement of FE due to plot geometry (5 to $15 \%$ ). Note that actual work capacity (WCa, ha $\mathrm{h}^{-1}$ ) decreased linearly with the FE and, thus, with the relevance of this analysis. The range of field efficiency found in this work (52\% - $84 \%$ ) agrees with those previously reported, with values of $70 \%$ provided by Troncoso et al., 2002 . 
Table 5 - Comparison of avoidable dead time TME (s and \% of effective time (TE)) and TE for every plot in both countries; 1 to13 in Brazil and 14 to 28 in Spain.

\begin{tabular}{|c|c|c|c|c|c|c|c|c|c|}
\hline & \multicolumn{4}{|c|}{ Brazil } & & \multicolumn{4}{|c|}{ Spain } \\
\hline & & TME (s) & TE (s) & TME (\% of TE) & & & TME (s) & $\mathrm{TE}(\mathrm{s})$ & TME (\% of TE) \\
\hline \multirow{5}{*}{$\begin{array}{l}3052 \\
\text { Towed }\end{array}$} & 1 & 302 & 10088 & 3.0 & \multirow{13}{*}{$\begin{array}{c}9090 \mathrm{X} \\
\text { Self-propelled }\end{array}$} & 14 & 504 & 21024 & $2.4(\mathrm{R})$ \\
\hline & 2 & 1190 & 7592 & 15.7 & & 15 & 832 & 5310 & $15.7(\mathrm{R})$ \\
\hline & 3 & 260 & 8102 & 3.2 & & 16 & 992 & 9016 & $11.0(\mathrm{R})$ \\
\hline & 4 & 6 & 1612 & 0.4 & & 17 & 114 & 11380 & 1.0 \\
\hline & 5 & 218 & 2442 & 8.9 & & 18 & 8 & 2576 & 0.3 \\
\hline \multirow{8}{*}{$\begin{array}{l}8050 \\
\text { Towed }\end{array}$} & 6 & 0 & 3688 & 0.0 & & 19 & 0 & 590 & 0.0 \\
\hline & 7 & 148 & 2240 & 6.6 & & 20 & 380 & 3616 & 10.5 \\
\hline & 8 & 4 & 1498 & 0.3 & & 21 & 26 & 2462 & 1.1 \\
\hline & 9 & 4 & 1586 & 0.3 & & 22 & 2 & 1726 & 0.1 \\
\hline & 10 & 62 & 6946 & 0.9 & & 23 & 0 & 1504 & 0.0 \\
\hline & 11 & 0 & 2348 & 0.0 & & 24 & 108 & 4626 & 2.3 \\
\hline & 12 & 550 & 7980 & 6.9 & & 25 & 64 & 3188 & 2.0 \\
\hline & 13 & 310 & 2638 & 11.8 & & 26 & 0 & 1144 & 0.0 \\
\hline & & & & & \multirow{2}{*}{$\begin{array}{l}8015 \\
\text { Towed }\end{array}$} & 27 & 1394 & 12892 & $10.8(\mathrm{R})$ \\
\hline & & & & & & 28 & 68 & 20534 & $0.3(\mathrm{R})$ \\
\hline
\end{tabular}

$\mathrm{R}=$ Reconfigured.

Table 6 - The relationship between geometry $(R 21 ; R 41)$ and FE in both countries.

\begin{tabular}{|c|c|c|c|c|c|c|c|c|c|}
\hline & \multicolumn{4}{|c|}{ Brazil } & & \multicolumn{4}{|c|}{ Spain } \\
\hline & Geometry and plot & $\begin{array}{l}\text { Effective time } \\
\text { TE (s) }\end{array}$ & $\begin{array}{c}\text { Accessory time } \\
\text { TA (s) }\end{array}$ & $\begin{array}{c}\text { Field efficiency } \\
\text { FE }\end{array}$ & & Geometry and plot & $\mathrm{TE}(\mathrm{s})$ & $\mathrm{TA}$ (s) & $\mathrm{FE}$ \\
\hline \multirow{12}{*}{$\begin{array}{l}8050 \\
\text { Towed }\end{array}$} & & & & $\%$ & \multirow{12}{*}{$\begin{array}{c}9090 \mathrm{x} \\
\text { Self-propelled }\end{array}$} & & & & $\%$ \\
\hline & $R 21(p 6)$ & 3688 & 970 & 79.18 & & R21 (p22) & 1726 & 862 & 66.69 \\
\hline & $R 21(p 7)$ & 2240 & 686 & 76.56 & & R21 (p25) & 3188 & 1968 & 61.83 \\
\hline & $R 21(p 11)$ & 2348 & 1048 & 69.14 & & $R 21$ (p24) & 4626 & 2970 & 60.90 \\
\hline & R41 (p9) & 1586 & 284 & 84.81 & & R21 (p18) & 2576 & 2180 & 54.16 \\
\hline & R41 (p12) & 7980 & 2656 & 75.03 & & R21 (p21) & 2462 & 2228 & 52.49 \\
\hline & \multirow[t]{6}{*}{ R41 (p8) } & 1498 & 650 & 69.74 & & R41 (p17) & 11380 & 2370 & 82.76 \\
\hline & & & & & & R41 (p19) & 590 & 130 & 81.94 \\
\hline & & & & & & R41 (p16) & 9016 & 5696 & 61.28 \\
\hline & & & & & & R41 (p23) & 1504 & 958 & 61.09 \\
\hline & & & & & & R41 (p20) & 3616 & 2444 & 59.67 \\
\hline & & & & & & R41 (p26) & 1144 & 990 & 53.61 \\
\hline
\end{tabular}

The differences in field efficiency (between 5 and $15 \%$ of the plots) were associated with the geometry of the plots in Figure 6 . The distance between the headlands and the point of the machine downloading is another fact that corroborates the increase of the TA (with correspondingly higher impact in the computation of field efficiency), together with a TE reduction (higher In row ground speed, Figure 6 lower line).

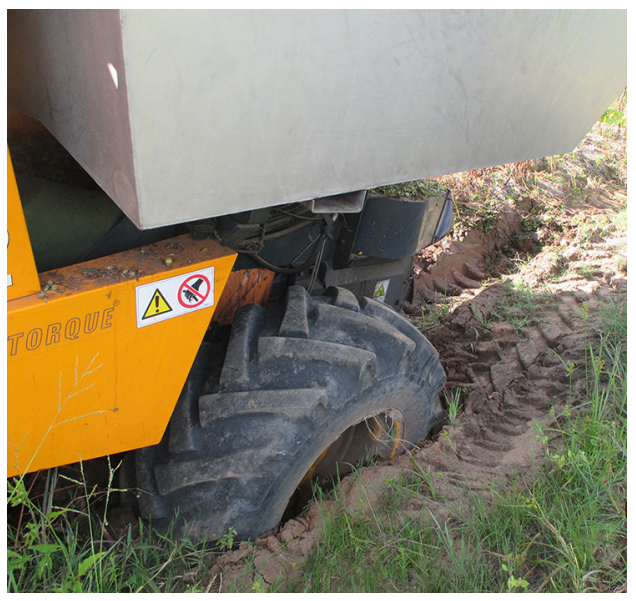

Figure $\mathbf{5}$ - Loss of trafficability in Plot 2 in Brazil due to soil moisture conditions.

\section{Quality of harvesting}

Table 7 compares grape losses in all 28 plots $(13$ in Brazil and 15 in Spain). Average soil grape losses (\% of vine productivity) were found to be highest for the management of Model 8050 (Brazil) compared to Model 3052 (Brazil) and Model 8015 (Spain): About $2 \%$ versus $1 \%$ and $1 \%$, respectively $(\mathrm{F}=8.0, p<0.01$, data not shown), all of them corresponding to the towed type. Undetached grapes on the plant can reach 12 and $23 \%$ in Brazil due to the use of wide wooden sticks for the trellises $(20 \mathrm{~cm}$ ) (Plots 11 and 13 in Table 7 compared to the $10 \mathrm{~cm}$ width in the rest of the plots in Brazil). Figures $7 \mathrm{~A}$ and $\mathrm{B}$ gives examples of sizeable undetached grapes losses with stick comparisons $(20 \mathrm{~cm}$ and $10 \mathrm{~cm})$ in Figures $7 \mathrm{~A}$ and $\mathrm{B}$, respectively. Under standard vibration conditions (450-480 bpm), plant losses are found to be $6 \%$ versus $1 \%$ for Model 3052 (Brazil) and Model 8015 (Spain), both towed, while being on average close to $0 \%$ 

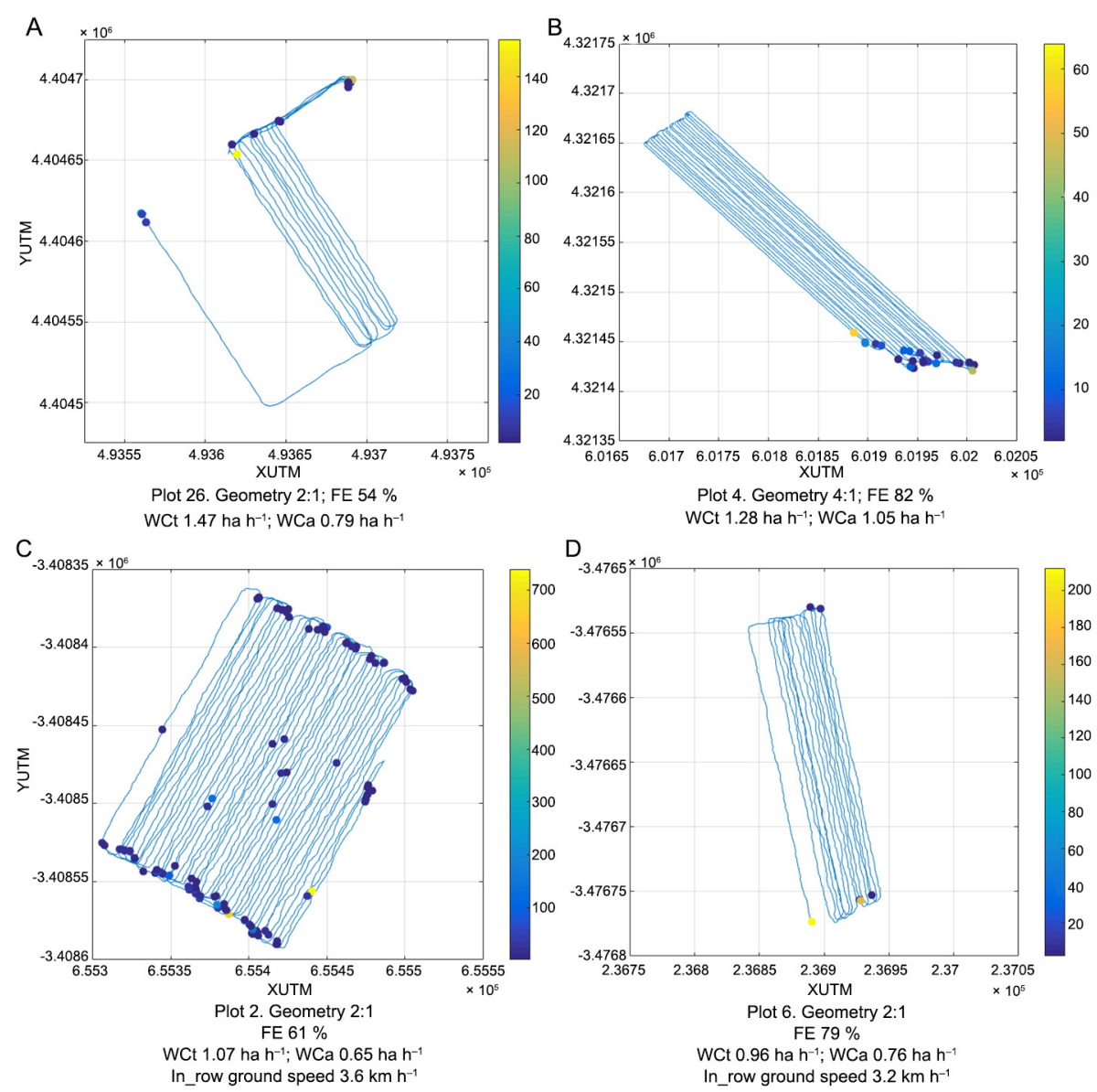

Figure 6 - Machine trajectories: blue lines indicate crop rows and circles establish machine stops, with color related to stop duration (s). Values of machine performance (WCt) and field efficiency (FE) are shown for varying plot geometries, ground speed and distance to download; Plots 26 and 4 in Spain, 2 and 6 in Brazil, are shown as A, B, C and D, respectively.

Table 7 - Comparative of losses of grapes and must between plots. Frequency (Freq.) and amplitude; Grape losses soil and plant; Vine yield and Must release.

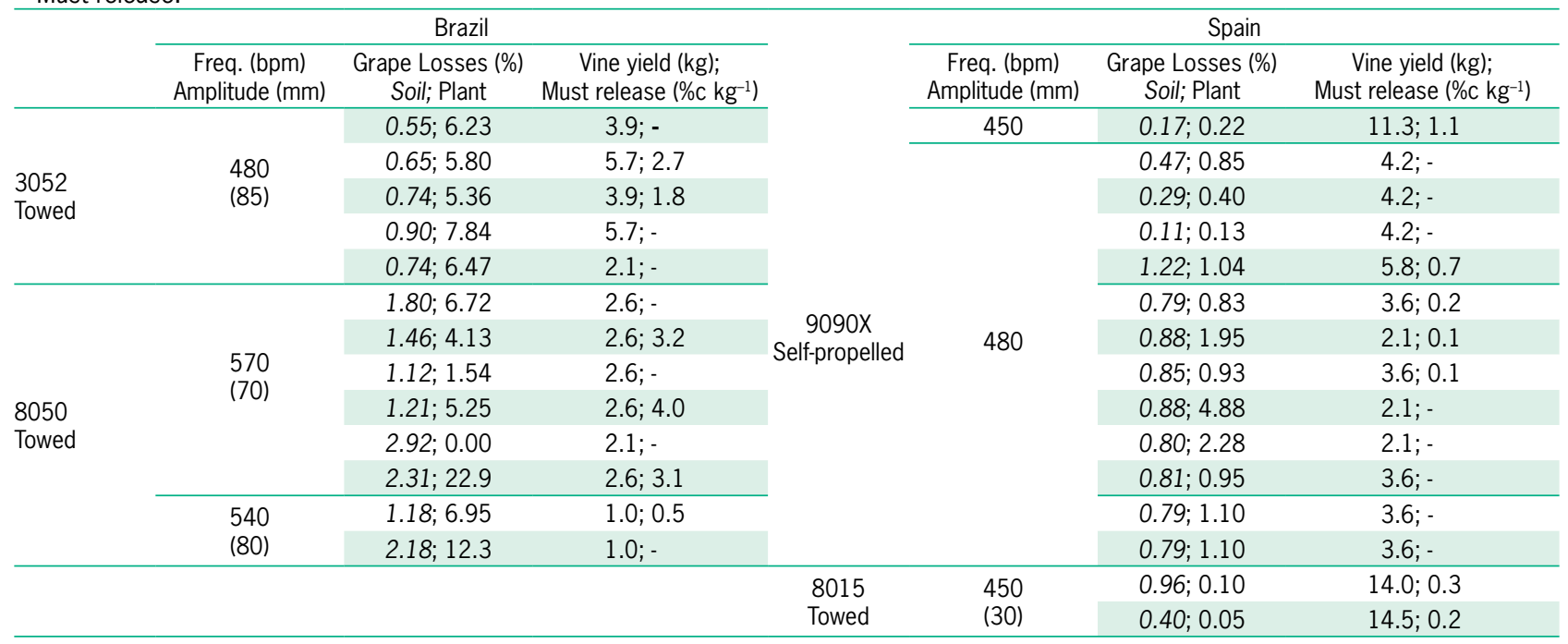




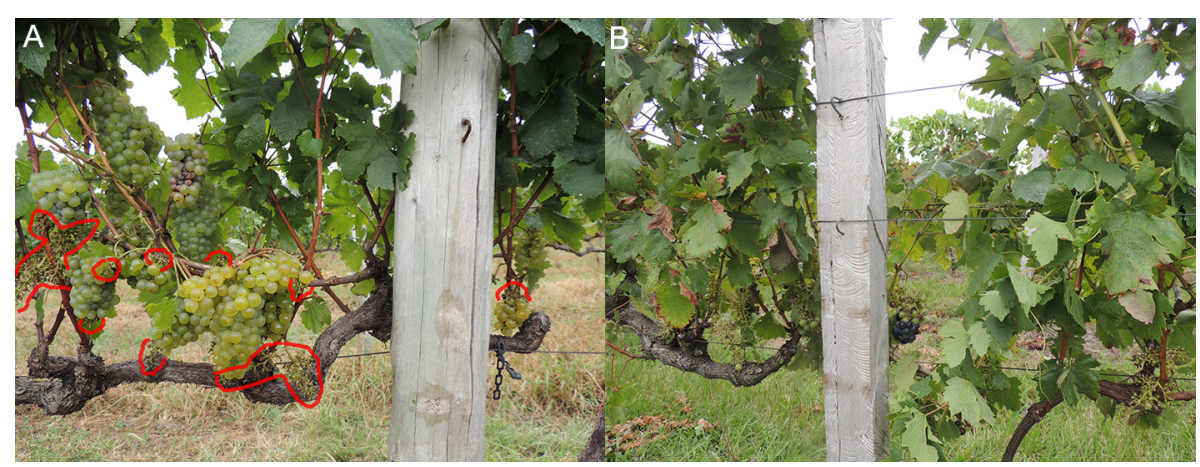

Figure 7 - Grapes not collected due to pole diameter in (A) $20 \mathrm{~cm}$ and (B) $10 \mathrm{~cm}$.

for the self-propelled 9090X (Spain), with significant differences $(\mathrm{F}=40.6 p<0.01$, data not shown). Thus, plant grape losses are generally higher than those lost on the soil. On the other hand, in the management of model 3052 (Brazil), plant losses (slightly higher than $6 \%$ ) are comparable to those found by (Troncoso et al., 2002) in Chile, $7 \%$ (plant and soil), a country also in the initial steps of mechanization. The lowest average grape losses (0\% - 1\%) referred to the management of Models 8015 and 9090X and corresponded to machine service providers operating at adequate settings according to operator knowledge (only 1 out of 13 plots in Spain showed plant losses above $4 \%$, while 11 out of 13 plots in Brazil did so). It is worth noting that plant grape losses may range between $0 \%$ to $6 \%$ according to vibration settings, as reported by Pezzi and Caprara, 2009; and Parenti et al., 2015.

Once grape losses are computed, harvest efficiency ( $\%$ of yield) can be determined for the management of Brazilian machines as approximately $93 \%$, compared to $98 \%$ for the self-propelled-machine in Spain. However, extreme harvest efficiency in Brazil can decline to 75 $\%$ in specific cases where 20 -cm wood sticks are used for canopy management which interfere with grape detachment (poor vibration transmission).

In this study, must release was shown to be higher in the management of towed machines in Brazil than for service providers in Spain $\left(2-4 \% \mathrm{c} \mathrm{kg}^{-1}\right.$ vs. virtually $0 \% \mathrm{c} \mathrm{kg}^{-1}$, respectively). Our must release values cannot be compared in absolute numbers to those of Pezzi and Caprara (2009) which were established in \%age of yield.

None of the operators in either Brazil or Spain performed frequency adjustments within plots. Neither were systematic criteria followed for red and white grapes in Spain by the service provider (Table 7). The vibration frequency ranges used for models 3052, 8015 and 9090X agreed with those tested by Pezzi and Caprara, 2009, Caprara and Pezzi, 2011 and those recommended by manufacturers (380-460 bpm for either self-propelled or towed machines), while the frequency used for Model 8050 in Brazil seems too high (540-570 bpm). Only for Model 8050 did Brazil differently adapt the settings according to grape type: in the case of that model, the operator decreased beat frequency and increased amplitude for red compared to white grapes 540 bpm (80 mm) versus $570 \mathrm{bpm}(70 \mathrm{~mm})$, respectively.

\section{Conclusions}

The conclusions can be summarized as follows:

Processing capacity in the management of machines was found to be higher in Spain, reaching $84 \%$ and above $100 \%$ for towed and self-propelled machines, respectively, versus $69 \%$ in Brazil with towed equipment.

In-row avoidable death time (TME, as \% of effective time) was found to be relevant to the actual management of the machines. In Spain, approximately $10 \%$ is related to reconfiguring vines for mechanical rather than manual harvest, as well as excessive ground speed; however, in Brazil, approximately up to $16 \%$ seems related to the loss of trafficability due to soil moisture, which is an uncommon event in Spain during harvest season.

Field efficiency ranged from 52 to $84 \%$ with the largest constraint being the distance to download, though a significant difference was also found relating to the varying geometry of the plots (higher FE for rectangular 4:1 compared to $2: 1$ ).

Harvest efficiency (\% of yield) can be designated as $94 \%$ in the actual management of Brazilian machines, compared to $98 \%$ in the self-propelled-machines in Spain. However, the extreme values for harvest efficiency in Brazil can decrease to $75 \%$ in specific cases when using $20-\mathrm{cm}$ wood sticks for canopy management, interfering with grape detachment.

Whenever Brazil incorporates self-propelled machines into their harvest fleet, an increase of $20 \%$ in ground speed compared to towed equipment can be expected, with corresponding increases in theoretical work capacity.

For machine settings related to grape and must losses, machine service providers (in the case of Spain) showed the best features (lowest losses), which is similar to the optimums found in the literature. There is still progress to be made in the training of machine operators in Brazil. 


\section{Acknowledgments}

The corresponding author gratefully acknowledges the financial support of $\mathrm{CNPq}$ (Conselho Nacional de Desenvolvimento Científico e Tecnológico).

\section{Authors' Contributions}

Conceptualization: da Costa Neto, W.V.; Barreiro, P.E. Data acquisition: da Costa Neto, W.V. Data analysis: da Costa Neto, W.V.; Barreiro, P.E.; Garrido-Izard, M. Design of Methodology: da Costa Neto, W.V.; Barreiro, P.E. Writing and editing: da Costa Neto, W.V.; Barreiro, P.E.; Garrido-Izard, M.

\section{References}

Arfelli, G.; Sartini, E.; Bordini, F.; Caprara, C.; Pezzi, F. 2010. Mechanical harvesting optimization and postharvest treatments to improve wine quality. Journal International des Sciences de la Vigne et du Vin 44: 101-115.

Caprara, C.; Pezzi, F. 2011. Measuring the stresses transmitted during mechanical grape harvesting. Biosystems Engineering 110: 97-105.

Caprara, C.; Pezzi, F. 2014. Evaluation of quality of harvested and mechanical aspects related to beater adjustments in mechanical grape harvesting. Transactions of the ASABE 57: 991-997.

Catania, P.; Vallone, M.; Pipitone, F. 2009. Analysis of the main factors influencing the quality of wines from mechanically harvested grapes. Journal of Agricultural Engeneering 4: 27-30.

Clary, C.D.; Steinhauer, R.E.; Frisinger, J.E.; Peffer, T.E. 1990. Evaluation of machines vs. hand-harvested Chardonnay. American Journal for Enology and Viticulture 41: 176-181.
Costa Neto, W.V.; Garrido-Izard, M.; Barreiro, P.; Domingues, F. 2017. First steps in the grape mechanization process in Brazil: quantitative features. CiGR Journal 2: 117-119.

Hendrickson, D.A.; Oberholster, A. 2017. Review of the impact of mechanical harvesting and optical berry sorting on grape and wine composition. Catalyst Discovery into Practice 1: 21-26.

Hunt, D.; Wilson, D. 2015. Farm Power and Machinery Management. Waveland Press, Long Grove, IL, USA.

Ministerio de Agricultura y Pesca, Alimentación y Medio Ambiente [MAGRAMA]. 2016. Agro-food statistics yearbook = Anuario de estadística agroalimentaria. Available at: http:// www.mapama.gob.es/estadistica/pags/anuario/2016/AE16.pdf [Accessed Oct 10, 2017] (in Spanish).

Parenti, A.; Spugnoli, P.; Masella, P.; Guerrini, L.; Benedettelli, S.; Di Blasi, S. 2015. Comparison of grape harvesting and sorting methods on factors affecting the must quality. Journal of Agricultural Engineering 456: 19-22.

Pezzi, F.; Caprara, C. 2009. Mechanical grape harvesting: investigation of the transmission of vibrations. Biosystems Engineering 103: 281-286.

Pezzi, F.; Martelli, R. 2015. Technical and economic evaluation of mechanical grape harvesting in flat hill vineyards. Transactions of the ASABE 58: 297-303.

Troncoso, J.C.; Riquelme, J.S.; Laurie, F.G.; Abarca, J.G. 2002. Evaluation of the relative advantages of mechanical harvesting of wine grapes in Central Chile. Agricultura Técnica 62: 1-11 (in Spanish, with abstract in English).

Vollmer, E.; Schwarz, H.P. 2013. Documentation of working time in different vineyard systems. Acta Horticulture 978: 385-390.

Witney, B. 1995. Choosing and Using Farm Machines. Land Technology, Edinburgh, Scotland. 